\title{
Comparison between Field Data and NASA Ames Wind Tunnel Data
}

Dave Corbus 


\section{Comparison between Field Data and NASA Ames Wind Tunnel Data}

\section{Dave Corbus}

Prepared under Task Nos. WER5.3101, WER6.2110

National Renewable Energy Laboratory

1617 Cole Boulevard, Golden, Colorado 80401-3393

303-275-3000 • www.nrel.gov

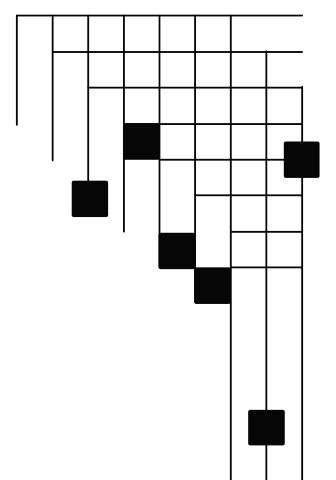




\section{NOTICE}

This report was prepared as an account of work sponsored by an agency of the United States government. Neither the United States government nor any agency thereof, nor any of their employees, makes any warranty, express or implied, or assumes any legal liability or responsibility for the accuracy, completeness, or usefulness of any information, apparatus, product, or process disclosed, or represents that its use would not infringe privately owned rights. Reference herein to any specific commercial product, process, or service by trade name, trademark, manufacturer, or otherwise does not necessarily constitute or imply its endorsement, recommendation, or favoring by the United States government or any agency thereof. The views and opinions of authors expressed herein do not necessarily state or reflect those of the United States government or any agency thereof.

Available electronically at http://www.osti.gov/bridge

Available for a processing fee to U.S. Department of Energy and its contractors, in paper, from:

U.S. Department of Energy

Office of Scientific and Technical Information

P.O. Box 62

Oak Ridge, TN 37831-0062

phone: 865.576 .8401

fax: 865.576 .5728

email: mailto:reports@adonis.osti.gov

Available for sale to the public, in paper, from:

U.S. Department of Commerce

National Technical Information Service

5285 Port Royal Road

Springfield, VA 22161

phone: 800.553 .6847

fax: 703.605.6900

email: orders@ntis.fedworld.gov

online ordering: http://www.ntis.gov/ordering.htm 


\section{Contents}

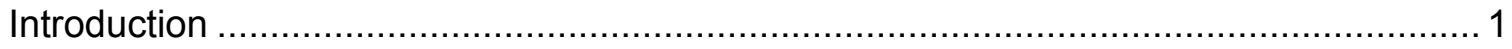

Methodology

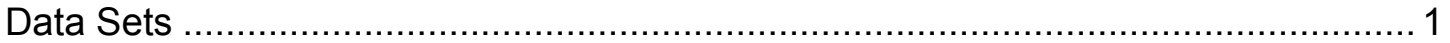

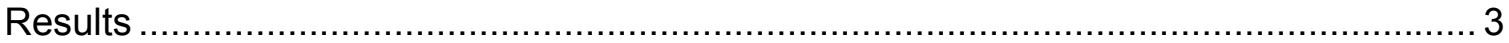

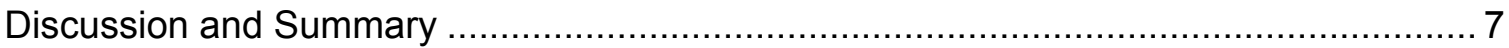

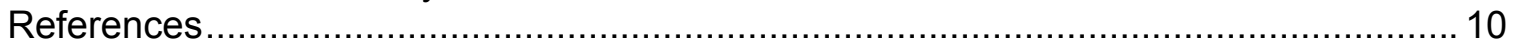

\section{List of Figures}

Figure 1. Yaw error for Phase $V$ data set ......................................................... 2

Figure 2. Wind speed and turbulence intensity for Phase $V$ data set .......................... 2

Figure 3. Turbulence intensity versus mean wind speed....................................... 3

Figure 4. Mean power versus mean wind speed .................................................. 4

Figure 5. Mean, maximum, and minimum power versus mean wind speed ................... 4

Figure 6 . Mean torque versus mean wind speed.................................................. 5

Figure 7. Mean thrust versus mean wind speed .................................................... 5

Figure 8. Mean root flap bending moment versus mean wind speed ......................... 6

Figure 9. Mean blade 1 and blade 3 root edge bending moment versus mean wind

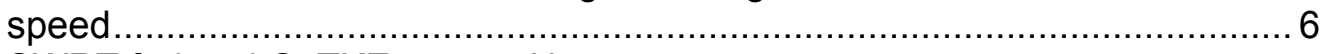

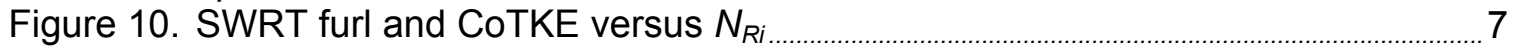

Figure 11. SWRT rotor thrust and model predictions with SN Wind and TurbSim ............ 8

Figure 12. UAE wind tunnel data for different wind speed "sweeps" .......................... 9 


\section{Introduction}

Wind Tunnel tests are an important way to obtain accurate data for validation of aeroelastic simulation models. A properly designed and implemented wind tunnel test provides quantitative aerodynamic and structural measurements that are geometrically and dynamically representative of full-scale wind turbines. The wind tunnel's aerodynamic environment is free from pronounced inflow anomalies that would otherwise be a factor in wind turbine tests that are conducted "in the field" (i.e., in an outside environment where the effects of turbulence are part of the inflow). Wind turbine aeroelastic models can be compared and validated to wind tunnel test data without having to consider the effects of turbulence. However, wind tunnel tests are much more expensive to conduct than field tests.

The objective of this analysis is to compare the measured data from the NASA Ames wind tunnel experiment to those collected in the field at the National Wind Technology Center (NWTC) with the same turbine configuration. The results of this analysis provide insight into which measurements can be made in the field as opposed to wind tunnel testing.

\section{Methodology}

Data sets from field measurements on the Unsteady Aerodynamics Experiment (UAE) [1] Phase $\mathrm{V}$ test turbine were collected and organized according to the type of measurements taken, the turbine configuration, and the inflow conditions during measurement. The field measurements were then compared to measurements from the UAE NASA Ames dataset [2] conducted in the wind tunnel using similar mean wind speeds and the same turbine operating parameters. The data sets were compared in terms of the turbine performance and loads, taking into consideration the turbulence intensity for the field measurements.

\section{Data Sets}

Only 16 data files were available from the Phase V UAE test campaign for comparison with the Phase VI UAE wind tunnel test data. It was originally envisioned that more data files would be available from the Phase V testing, but analysis of the Phase V data revealed that only 16 of the 26 files could be used because they were the only ones with a fixed configuration. The components of the fixed configuration included upwind, three-degree pitch, two-bladed, and teetered-hub. The files are 10 minutes in length, and the sampling rate is approximately $500 \mathrm{hz}$. There were two differences between the configurations used for the Phase V and Phase VI turbines that were not discovered until after the analysis began. One major difference was that the blades were different: the Phase V blades were constant-chord, optimally twisted, and the Phase VI blades were twisted and tapered. Another difference between the datasets was that the Phase V data had varying yaw errors between -1 and -7 degrees, whereas the Phase VI data had the yaw locked at zero degrees. Despite the differences between the two data sets, a comparison was conducted. Figure 1 shows a plot of the yaw error for the Phase V data set, and Figure 2 shows the turbulence intensity and wind speeds for the Phase V data set. Figure 3 is a plot of turbulence intensity versus mean wind speed. 
Yaw Error for Phase V Data Set

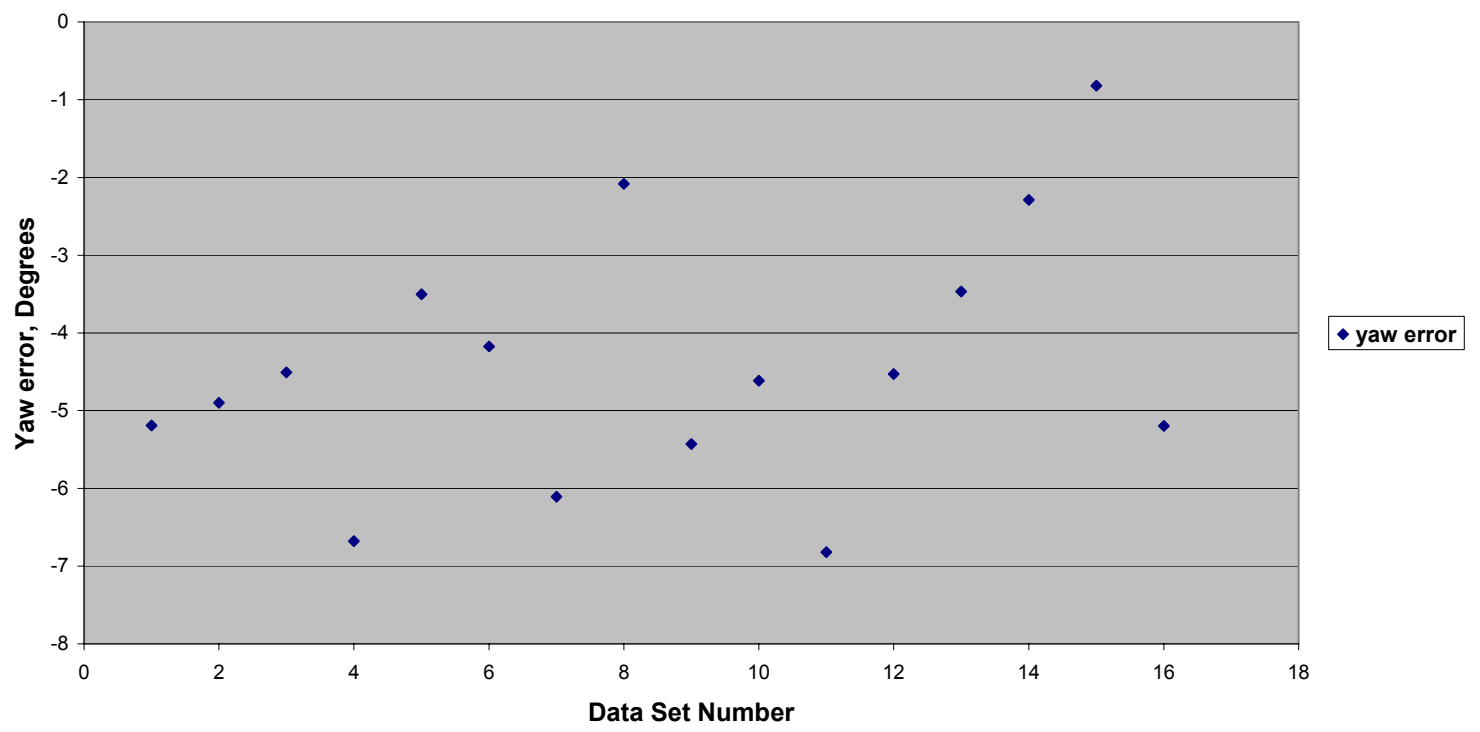

Figure 1. Yaw error for Phase V data set

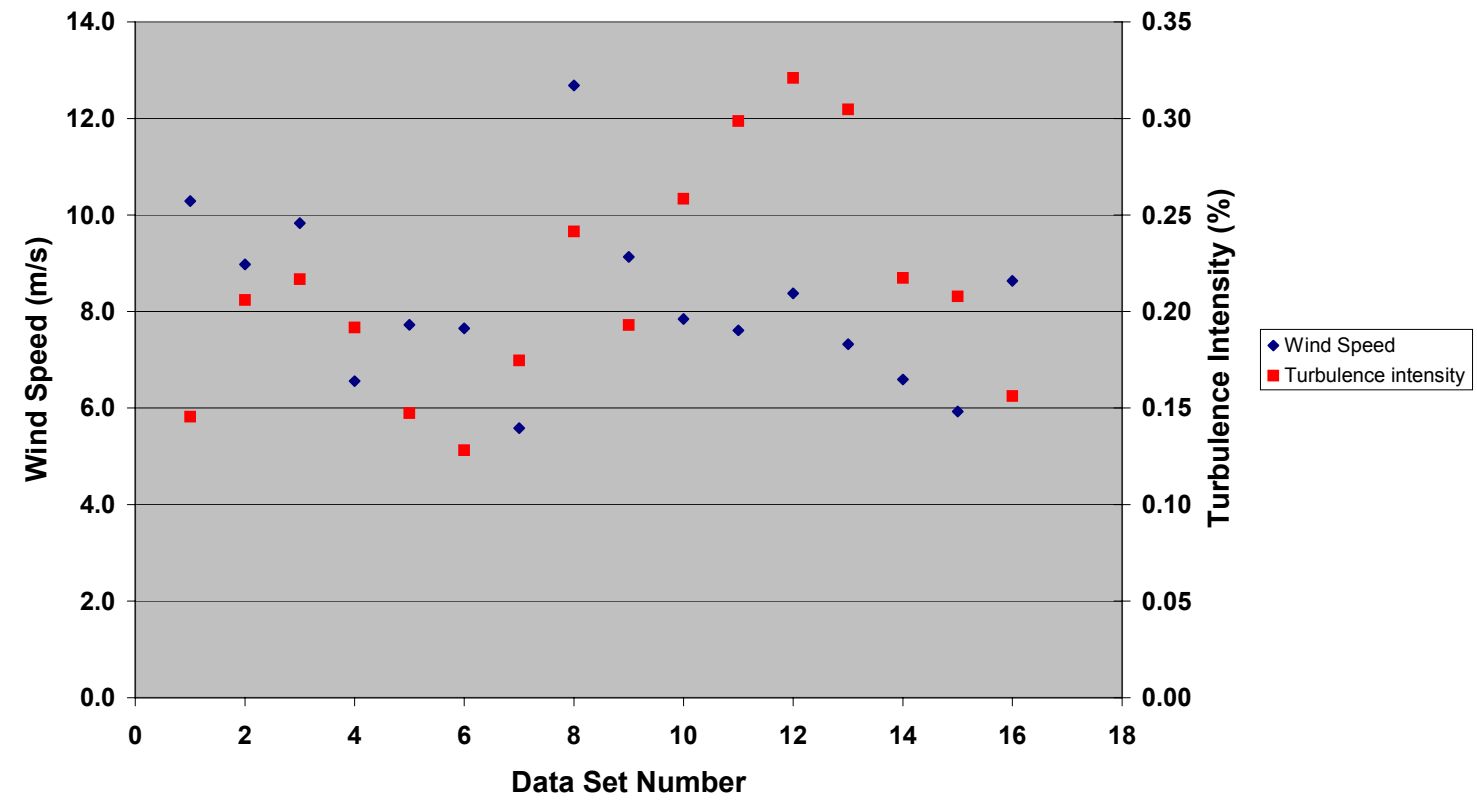

Figure 2. Wind speed and turbulence intensity for Phase V data set 


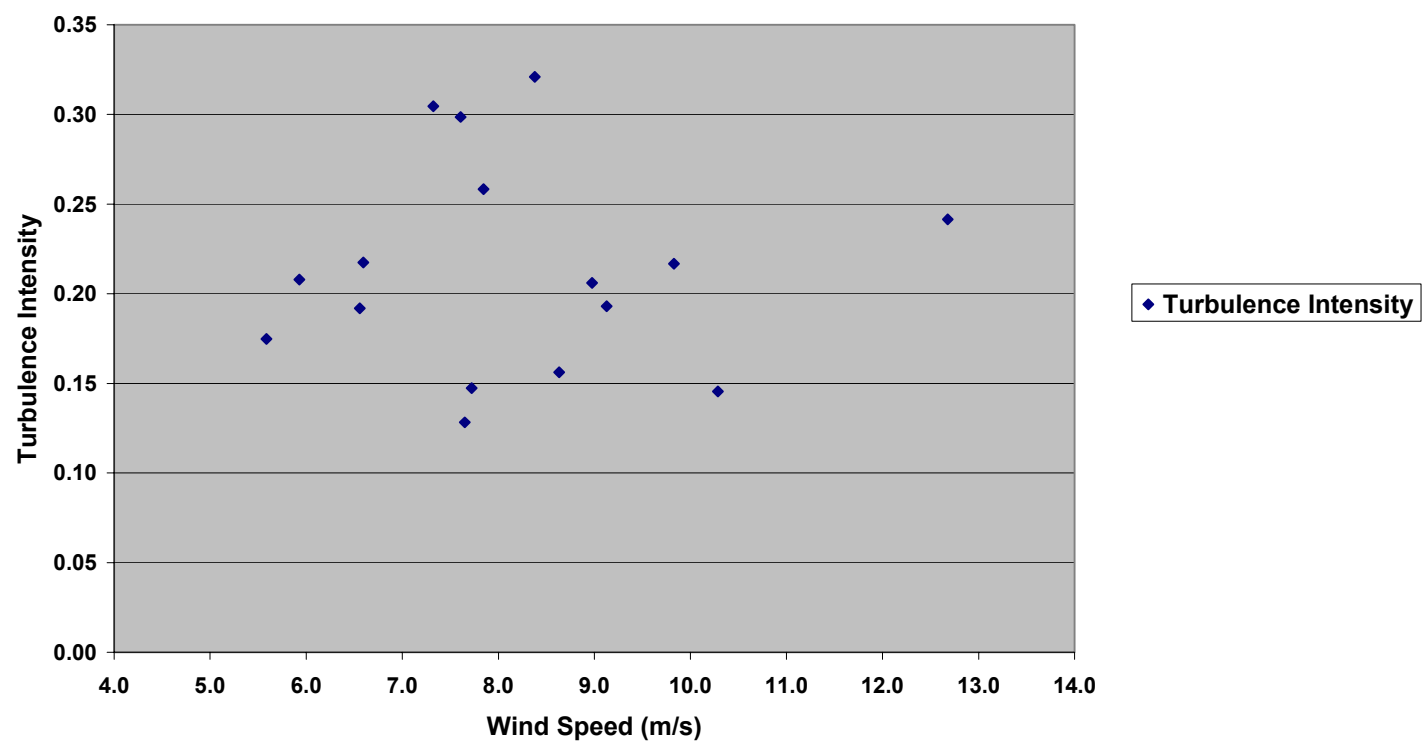

Figure 3. Turbulence intensity versus mean wind speed

\section{Results}

As expected, the high turbulence levels in the field measurements produced different aerodynamic phenomena than those seen in the wind tunnel; however, there were also some similar phenomena under certain measurement conditions. While it is impossible to quantify these differences with the available datasets, this section shows trends in the data and discusses the effects of turbulence.

Figures 4 shows a plot of mean power versus mean wind speed for the Phase V and Phase VI datasets. All power from the field $\mathrm{V}$ dataset is converted to sea level power by using the density of air at sea level as measured in the wind tunnel test. Variations in the power at a given wind speed for the Phase V field test can be partially explained by variations in the turbulence intensity: higher turbulence intensities may result in slightly lower power output for a given wind speed.

As expected, the effect of turbulence becomes more of a factor at higher wind speeds. The two data sets show similar mean power output at wind speeds up to about $7 \mathrm{~m} / \mathrm{s}$ when the effects of turbulence are small, but at $9 \mathrm{~m} / \mathrm{s}$ and above, the mean power outputs vary by $25 \%$ or more. 


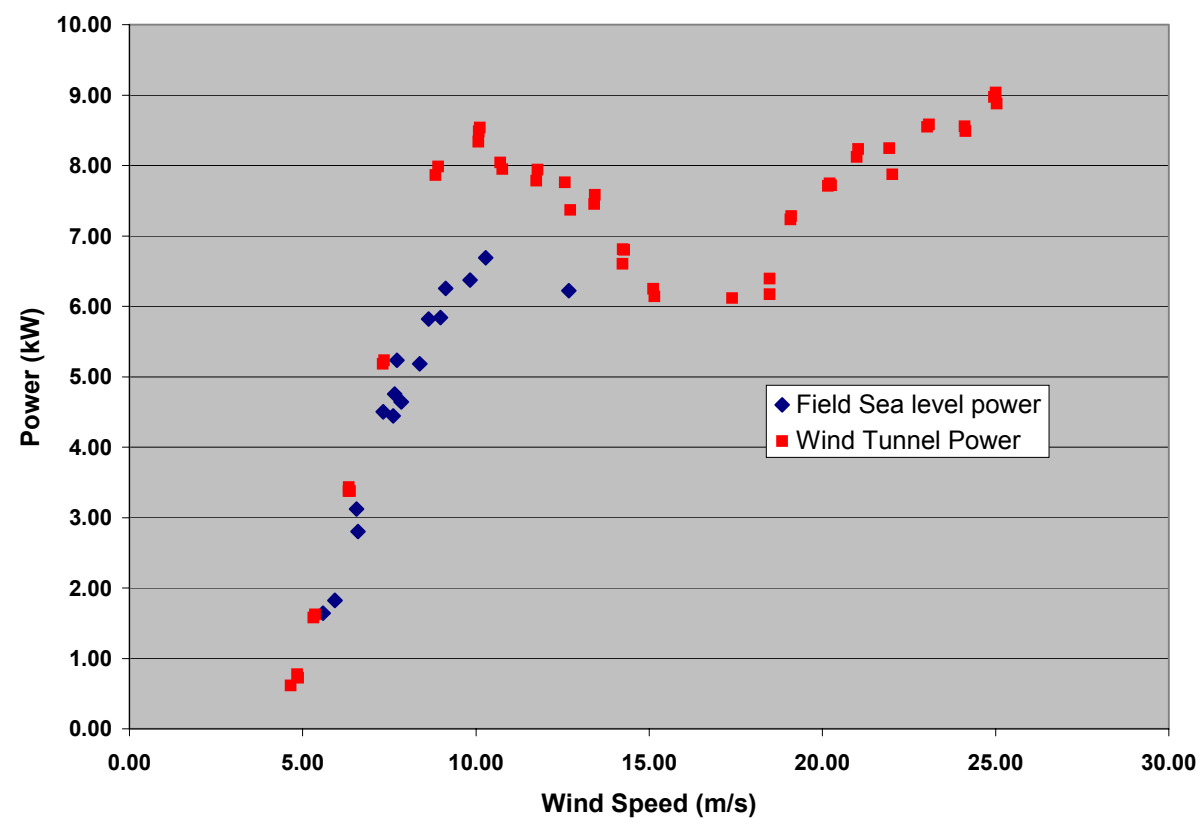

Figure 4. Mean power versus mean wind speed

Figure 5 shows power versus mean wind speed, as well as maximum and minimum power. Note that the minimum power from the field data can be negative.



Figure 5. Mean, maximum, and minimum power versus mean wind speed 
Figures 6 through 9 show plots of torque, thrust, blade flap bending moment, and edge bending moment versus mean wind speed.

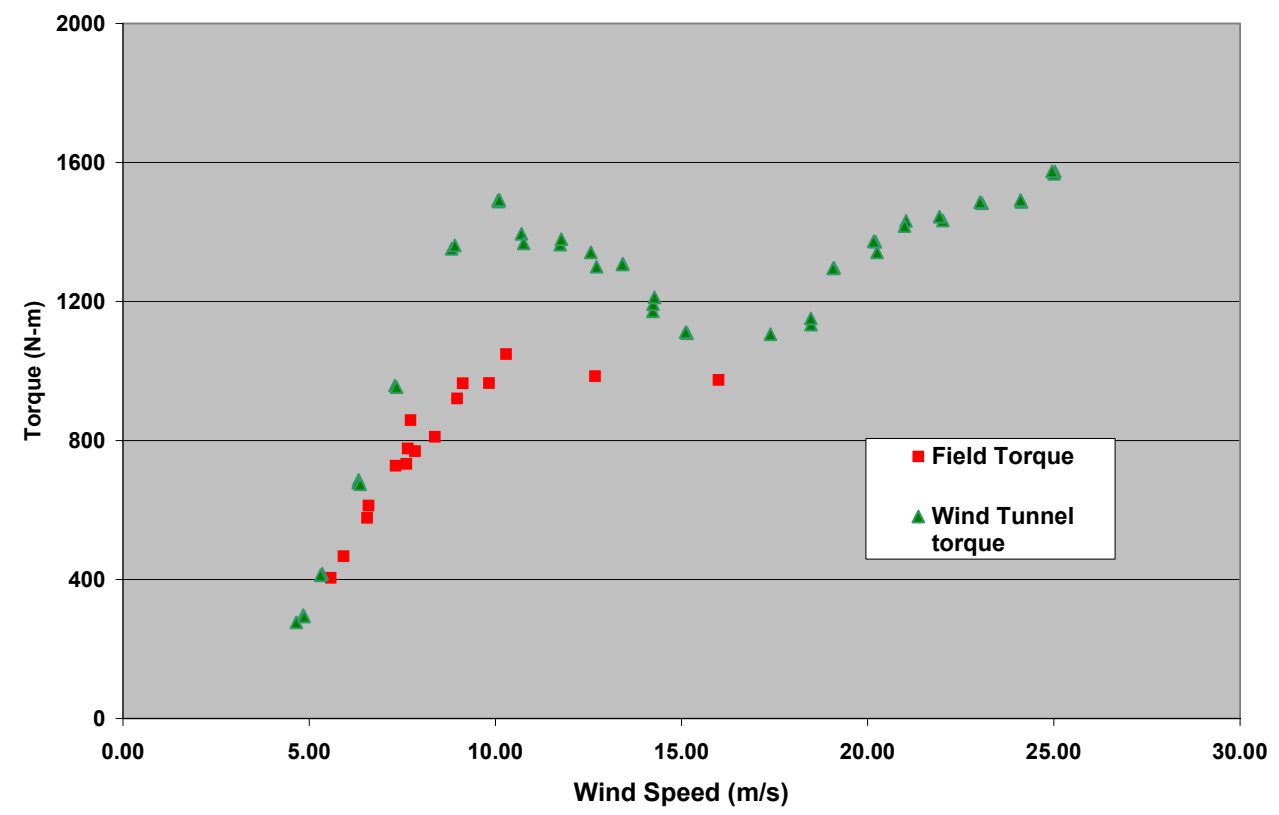

Figure 6. Mean torque versus mean wind speed

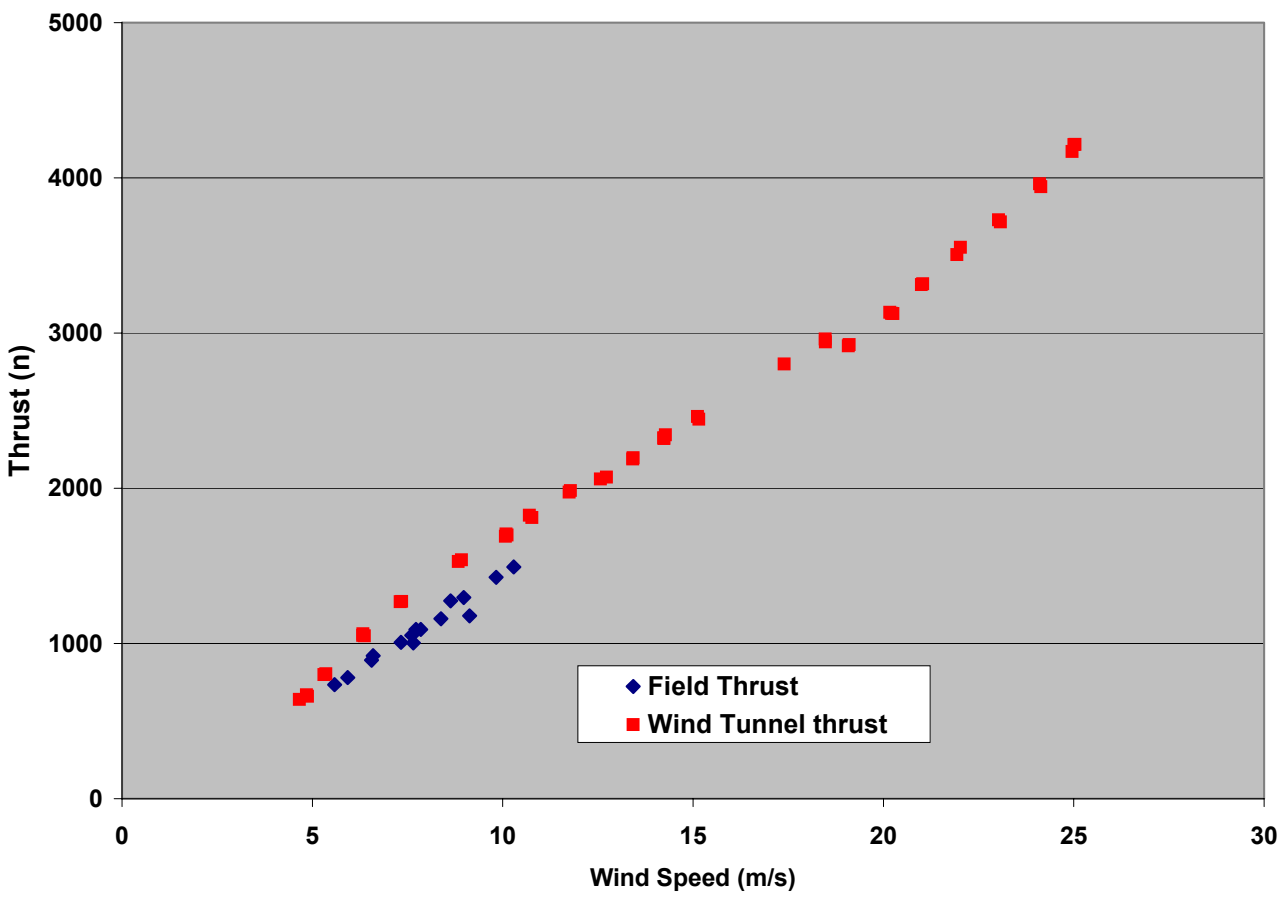

Figure 7. Mean thrust versus mean wind speed 


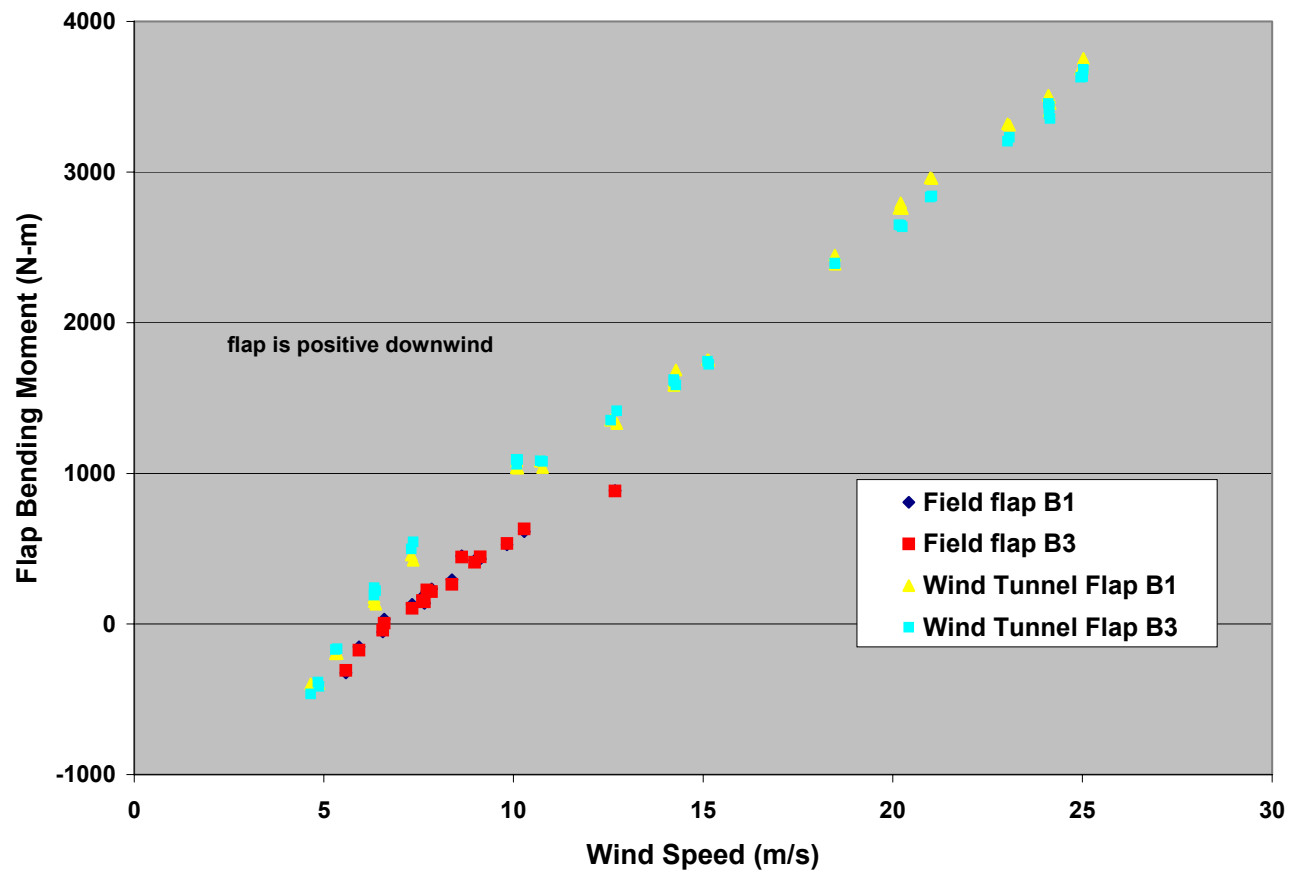

Figure 8. Mean root flap bending moment versus mean wind speed

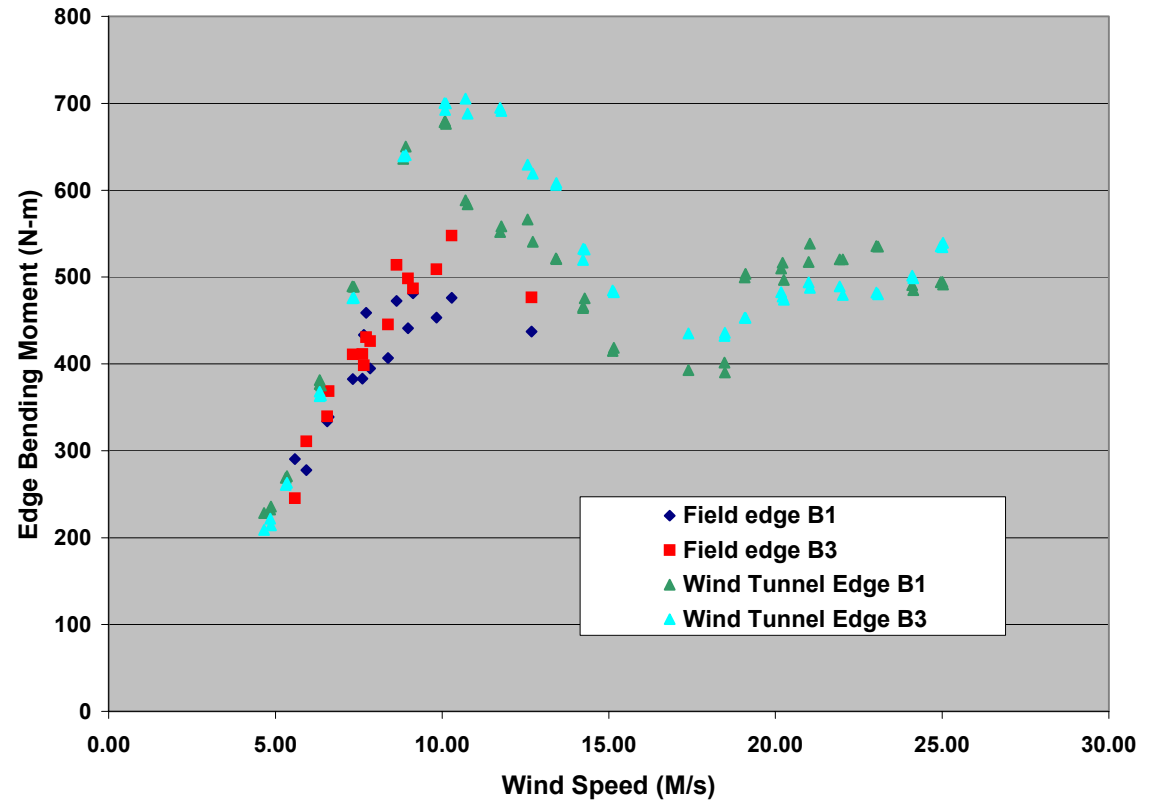

Figure 9. Mean blade 1 and blade 3 root edge bending moment versus mean wind speed 


\section{Discussion and Summary}

Field testing includes the effects of turbulence; therefore, data are typically averaged over a 10minute time span. The maximum values for loads and power for field test data will be higher than the instantaneous wind tunnel data, but the means will always be lower as the effects of turbulence reduce the magnitude of the measurements conducted. This was seen in the results of the previous section. The averaging time for field measurements is important: a comparison of 1minute data to 10-minute data will show higher mean measurements for the 1-minute data.

Turbulence intensity is just one parameter for characterizing the effects of turbulence [3, 4]. Detailed measurements of the inflow can be made to characterize the turbulence in terms of atmospheric parameters such as the Richardson number $\left(N_{R i}\right)$ or the Reynolds stresses. The $N_{R i}$ can be useful in explaining turbulence because it represents the ratio of turbulence generation by buoyancy (i.e., thermal) to wind shear (i.e., mechanical) forces. A negative value of $N_{R i}$ represents unstable or convective conditions, a value of zero represents neutral, and positive values signify a stable flow. The Reynolds stresses are the product of the turbulent or fluctuating (i.e., zero-mean) component velocities (i.e., longitudinal, transverse or crosswind, and vertical velocities), and they can be measured with a sonic anemometer and used to characterize the turbulence.

Analysis of other turbine tests at the NWTC can be helpful in understanding the relationship between turbulence and field test data. Figure 10 plots the response of the Small Wind Research Turbine (SWRT) to furl (i.e., turbine overspeed protection) and coherent turbulent kinetic energy (i.e., an indicator of the coherent turbulence) and shows the dependence of these parameters on the $N_{R i}$. The plot also shows the maximum load response from the Advanced Research Turbine (ART) at the NWTC. Note that the SWRT and ART sites are different locations at the NWTC so the turbulence is slightly different [5].

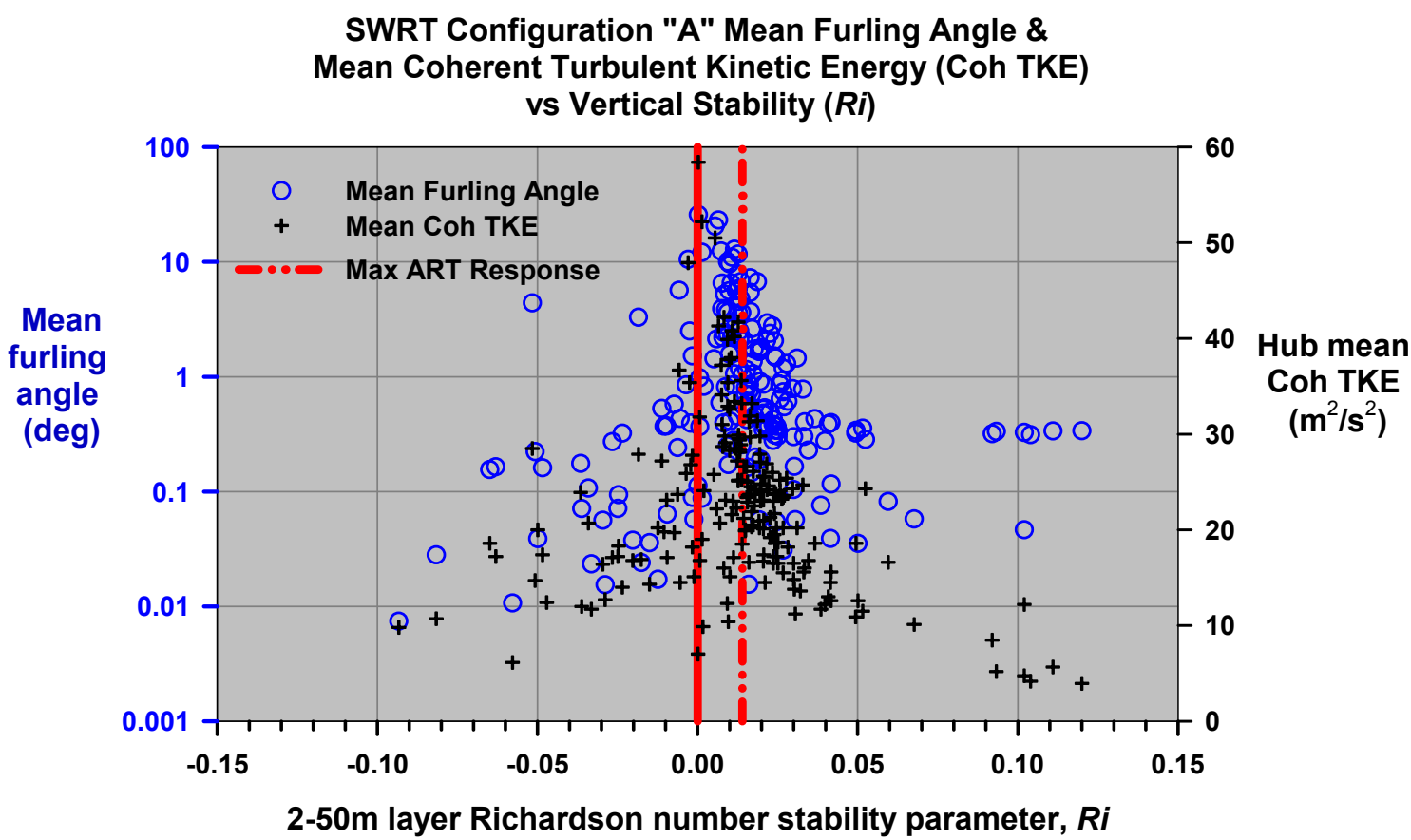

Figure 10. SWRT furl and CoTKE versus $N_{R i}$ 
NREL continues to conduct work on the effects of turbulence on wind turbine performance and loads. The ability to simulate coherent structures of turbulence for input into aeroelastic models of wind turbines has been improved with the latest version of TurbSim [6], a turbulence simulator. TurbSim can generate coherent turbulent structures with temporal and spatial scaling that reflect the actual turbulence measured at a site. This allows modelers to compare field test data to aeroelastic simulation results with a high degree of confidence that the effects of inflow are taken into account. It also allows models that have been validated with wind tunnel data to include the effects of turbulence in the simulations.

Aeroelastic modeling using the FAST model of the SWRT used both a simplified turbulent input (SNWind) and the TurbSim input [5]. TurbSim can generate coherent turbulent structures with temporal and spatial scaling that reflect the actual turbulence at site 1.4 at the NWTC where the SWRT test was conducted. The SWRT analysis used an $8 \times 8$ meter grid of points across the rotor disc and specific inflow data measured and calculated for each TurbSim file for the following: gradient $N_{R i}$, power law exponent, friction or shear velocity, and the cross correlation coefficients for the turbulent or fluctuating (i.e., zero-mean) component velocities (i.e., longitudinal, transverse or crosswind, and vertical velocities, U', V', and W').

The comparison showed that the 10-minute mean statistics were the same regardless of the inflow model, but the maximums and minimums were different. Figure 11 shows a plot of rotor thrust for the SWRT turbine from the test data and modeled results from the SNWIND turbulence and TurbSim models.



Figure 11. SWRT rotor thrust and model predictions with SN Wind and TurbSim 
Analysis of the UAE wind tunnel test shows that even in a controlled environment like a wind tunnel, test results can be affected by how the test is conducted. Figure 12 shows power versus wind speed for UAE test data. The results differ depending on how the wind speed was approached. The testing was conducted by "sweeping" through a range of wind speeds. As can be seen from the sweep up and sweep down power curves, there is a hysteresis to the blade stall. This is not an artifact of wind tunnel testing but the actual way the wind turbine responds to changes in wind speed.

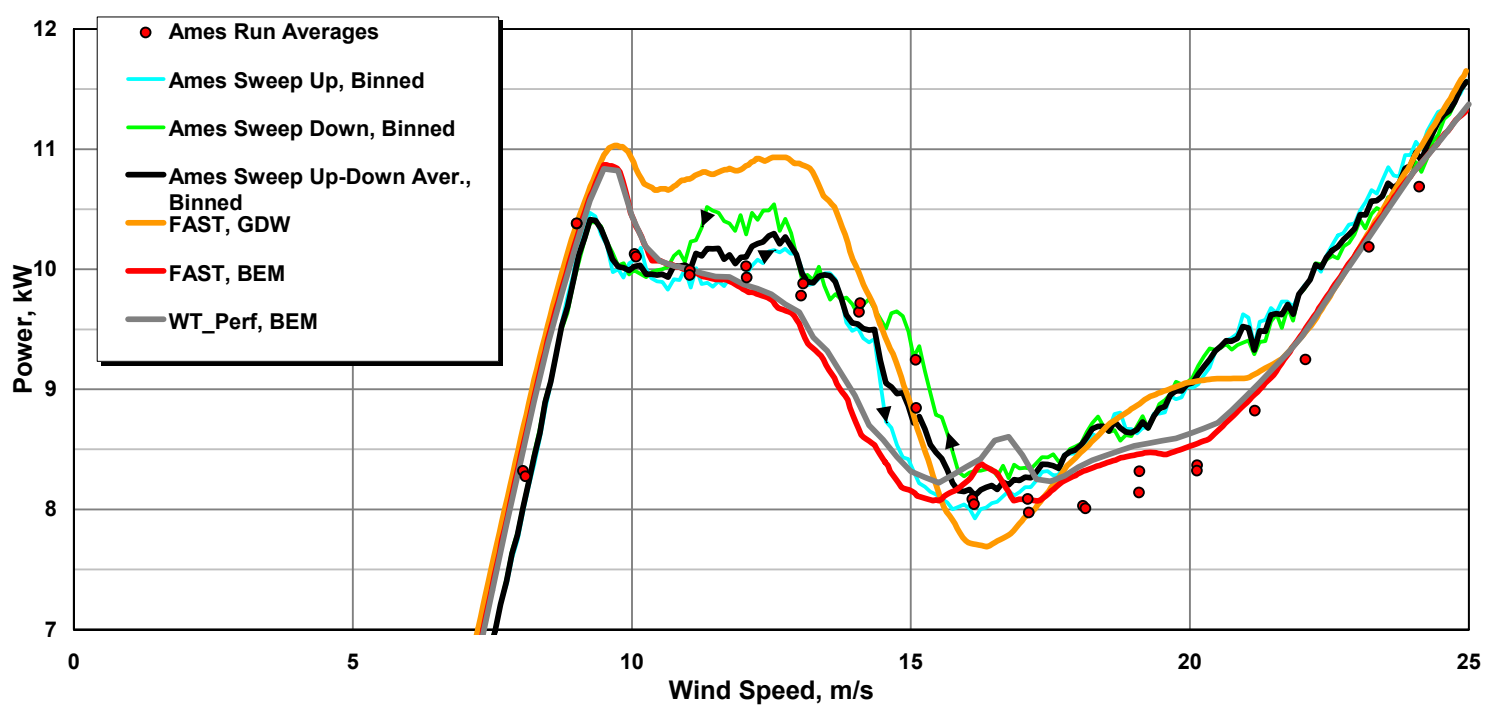

Figure 12. UAE wind tunnel data for different wind speed "sweeps"

The relationship between field test data, wind tunnel test data, and the ability to model turbulence with inflow models that are used as preprocessors to wind turbine aeroelastic simulation models is important. Although it would be best to validate models with wind tunnel data, wind tunnel tests are extremely expensive and not always possible to conduct. In addition, models validated by wind tunnel tests also need to include the effects of turbulence so that real world conditions (i.e., in the field) can be modeled. Comparing field test data to wind tunnel test data is needed to determine if field test data can be used to validate models in lieu of wind tunnel data; however, this analysis has shown that the comparison between UAE wind tunnel data and field test data was not conclusive due to insufficient data and differences in the wind tunnel and field test wind turbine configurations. 


\section{References}

[1] Hand, M.M.; Simms, D.A.; Fingersh, L.J.; Jager, D.W.; Cotrell, D. (2001). Unsteady Aerodynamics Experiment Phase V: Test Configuration and Available Data Campaigns. NREL/TP-500-29491. Golden, CO: National Renewable Energy Laboratory, 154 pp.

[2] Hand, M.M.; Simms, D.A.; Fingersh, L.J.; Jager, D.W.; Cotrell, J.R.; Schreck, S.; Larwood, S.M. (2001). Unsteady Aerodynamics Experiment Phase VI: Wind Tunnel Test Configurations and Available Data Campaigns. NREL/TP-500-29955. Golden, CO: National Renewable Energy Laboratory, $298 \mathrm{pp}$.

[3] Kelley, N.; Shirazi, M.; Jager, D.; Wilde, S.; Adams, J.; Buhl, M.; Sullivan, P.; Patton, E. (2004). “Lamar Low-Level Jet Program Interim Report," NREL TP-500-34593. Golden, CO: National Renewable Energy Laboratory.

[4] Sutherland, H. J.; Kelley, N. D.; Hand, M. M. (2003). "Inflow and Fatigue Response of the NWTC Advanced Research Turbine." Collection of the 2003 ASME Wind Energy Symposium Technical Papers at the 41st AIAA Aerospace Sciences Meeting and Exhibit, 6-9 January 2003, Reno, Nevada. New York: American Institute of Aeronautics and Astronautics, Inc. (AIAA) and American Society of Mechanical Engineers (ASME); pp. 214-224; NREL/CP-500-35270.

[5] Corbus, D., Prascher, D. (2005). "Analysis and Comparison of Test Results from the Small Wind Research Turbine Test Project." Collection of the 2005 ASME Wind Energy Symposium Technical Papers Presented at the $43^{\text {rd }}$ AIAA Aerospace Sciences Meeting and Exhibit, 10-13 January 2005, Reno, NV, Washington, D.C.: American Institute of Aeronautics and Astronautics, NREL/CP-500-36891.

[6] NWTC Design Codes (TurbSim by Neil Kelley, Bonnie Jonkman). http://wind.nrel.gov/designcodes/preprocessors/turbsim/. Last modified 26-May-2005; accessed 26-May-2005. 


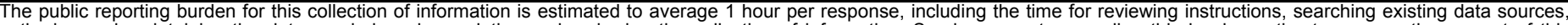

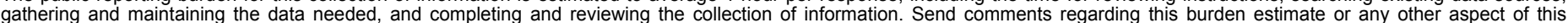

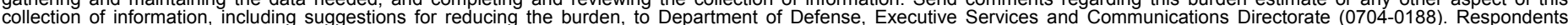

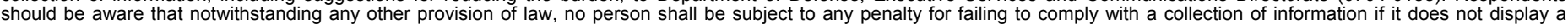

should be aware that notwilhstanding

PLEASE DO NOT RETURN YOUR FORM TO THE ABOVE ORGANIZATION.

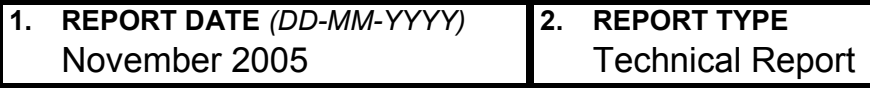

4. TITLE AND SUBTITLE

Comparison between Field Data and NASA Ames Wind Tunnel

Data
3. DATES COVERED (From - To) January - August 2005

5a. CONTRACT NUMBER

DE-AC36-99-G010337

5b. GRANT NUMBER

5c. PROGRAM ELEMENT NUMBER

5d. PROJECT NUMBER

NREL/TP-500-38285

5e. TASK NUMBER

WER6.2110

5f. WORK UNIT NUMBER
7. PERFORMING ORGANIZATION NAME(S) AND ADDRESS(ES)

National Renewable Energy Laboratory

1617 Cole Blvd.

Golden, CO 80401-3393
8. PERFORMING ORGANIZATION REPORT NUMBER

NREL/TP-500-38285

9. SPONSORING/MONITORING AGENCY NAME(S) AND ADDRESS(ES)

10. SPONSOR/MONITOR'S ACRONYM(S) NREL

11. SPONSORING/MONITORING AGENCY REPORT NUMBER

12. DISTRIBUTION AVAILABILITY STATEMENT

National Technical Information Service

U.S. Department of Commerce

5285 Port Royal Road

Springfield, VA 22161

13. SUPPLEMENTARY NOTES

14. ABSTRACT (Maximum 200 Words)

The objective of this analysis is to compare the measured data from the NASA Ames wind tunnel experiment to those collected in the field at the National Wind Technology Center (NWTC) with the same turbine configuration. The results of this analysis provide insight into what measurements can be made in the field as opposed to wind tunnel testing.

\section{SUBJECT TERMS}

wind energy; small wind research turbine; NASA Ames; wind tunnel experiment; NWTC

\begin{tabular}{|c|c|c|}
\hline $\begin{array}{l}\text { a. REPORT } \\
\text { Unclassified }\end{array}$ & $\begin{array}{l}\text { b. ABSTRACT } \\
\text { Unclassified }\end{array}$ & $\begin{array}{l}\text { c. THIS PAGE } \\
\text { Unclassified }\end{array}$ \\
\hline
\end{tabular}

\begin{tabular}{l|l|} 
17. & LIMITATION \\
OF ABSTRACT & 18. $\begin{array}{l}\text { NUMBER } \\
\text { OF PAGES } \\
\text { UL }\end{array}$ \\
\end{tabular}

19a. NAME OF RESPONSIBLE PERSON

19b. TELEPHONE NUMBER (Include area code) 